\title{
A gold-nanoparticle stoppered [2]rotaxane
}

Ulfkjær, Anne; Nielsen, Frederik W; Al-Kerdi, Hana; Ru, Tamara; Nielsen, Zaki K; Ulstrup, Jens; Sun, Lanlan; Moth-Poulsen, Kasper; Zhang, Jingdong; Pittelkow, Michael

\section{Published in:}

Nanoscale

Link to article, DOI:

$10.1039 / \mathrm{c} 8 \mathrm{nr} 01622 \mathrm{~d}$

Publication date:

2018

Document Version

Peer reviewed version

Link back to DTU Orbit

Citation (APA):

Ulfkjær, A., Nielsen, F. W., Al-Kerdi, H., Ru, T., Nielsen, Z. K., Ulstrup, J., Sun, L., Moth-Poulsen, K., Zhang, J., \& Pittelkow, M. (2018). A gold-nanoparticle stoppered [2]rotaxane. Nanoscale, 10(19), 9133-9140.

https://doi.org/10.1039/c8nr01622d

\section{General rights}

Copyright and moral rights for the publications made accessible in the public portal are retained by the authors and/or other copyright owners and it is a condition of accessing publications that users recognise and abide by the legal requirements associated with these rights.

- Users may download and print one copy of any publication from the public portal for the purpose of private study or research.

- You may not further distribute the material or use it for any profit-making activity or commercial gain

- You may freely distribute the URL identifying the publication in the public portal

If you believe that this document breaches copyright please contact us providing details, and we will remove access to the work immediately and investigate your claim 


\section{Journal Name}

\section{A gold-nanoparticle stoppered [2]rotaxane}

Received 00th January 20xx, Accepted 00th January 20xx

DOI: $10.1039 / x 0 x \times 00000 x$

www.rsc.org/

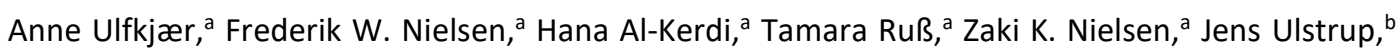
Lanlan Sun, ${ }^{c}$ Kasper Moth-Poulsen, ${ }^{*, c}$ Jingdong Zhang, ${ }^{*, b}$ and Michael Pittelkow. ${ }^{* a}$

The construction of molecular machines has captured the imagination of scientist for decades. Despite significant progress in the synthesis and studies of the properties of small-molecule components (smaller than 2-5 kilo Daltons) challenges regarding incorporation of molecular components into real devices are still eminent. Nano-sized molecular machines operate the complex biological machinery of life, and the idea of mimicking the amazing functions using artificial nanostructures is intriguing. Both in small-molecule molecular machine components and in many naturally occurring molecular machines, mechanically interlocked molecules and structures are key functional components. In this work we describe our initial efforts to interface mechanically-interlocked molecules and gold-nanoparticles (AuNPs); the molecular wire connecting the AuNPs is covered in an insulating rotaxane-layer, thus mimicking the macroscopic design of a copper wire. Taking advantage of recent progress in the preparation of supramolecular complexes of the cucurbit[7]uril (CB[7]) macrocycle, we have prepared a bis-thiol functionalised pseudo-rotaxane that enables us to prepare a AuNP-stoppered [2] rotaxane in water. The pseudo-rotaxane is held together extremely tightly $\left(K_{\mathrm{a}}>10^{13} \mathrm{M}^{-1}\right), K_{\mathrm{a}}$ being the association constant. We have studied the solution and gas phase guest-host chemistry using NMR spectroscopy, mass spectroscopy, and electrochemistry. The bis-thiol functionalised pseudo-rotaxane holds, further a ferrocene unit in the centre of the rotaxane; this ferrocene unit enables us to address the system in detail with and without CB[7] and AuNPs using electrochemical methods.

\section{Introduction}

Mechanically-interlocked molecules are of significant importance for the development of molecular machines at the molecular level.1-3 At the small-molecule level the work of Sauvage, Sanders, Leigh, Stoddart, and others since the 1970's has enabled the preparation of complex structures ranging from rotaxanes through catenanes to molecular knots. ${ }^{1-4}$ Exploitation of the unique properties of these structures has enabled complex operations such as unidirectional motion and on-offswitches for electronic components. ${ }^{1-5}$ The importance of naturally occurring systems that feature mechanicallyinterlocked structures are being realised in these years. The discovery of knotted DNA strands and lasso peptides are recent examples. ${ }^{6,7}$

Nano-engineering offers unique opportunity for bridging the gap between the many-nanometre size-regimes of the biological world and the Ångström world of small molecules. Artificial molecular machine immobilized surfaces (AMMISs),

a. Department of Chemistry, University of Copenhagen, Universitetsparken 5, DK2100 Copenhagen, Denmark.E-mail: pittel@chem.ku.dk.

b. Department of Chemistry, Technical University of Denmark, Kemitorvet, Building 207, DK-2800 Kongens Lyngby, Denmark.E-mail: jz@kemi.dtu.dk.

Department of Chemical and Biological Engineering, Chalmers University of Technology, Kemivägen 4, SE-41296 Gothenburg, Sweden. E-mail: kasper.mothpoulsen@chalmers.se

+ Electronic Supplementary Information (ESI) available: Experimental procedures, spectral characterisation data, details of the binding studies, and a description of the electrochemical measurements. See DOI: 10.1039/x0xx00000x where for example (pseudo)rotaxanes have been incorporated onto gold surfaces, are examples of this. ${ }^{8-10}$ The preparation of metallic nanoparticles (NPs) with well controlled size, multifarious functional groups and manipulation of their properties has revolutionized nanoscience and nanotechnology. The most studied metal NPs are gold nanoparticles (AuNPs), now a core nanoscale physical entity with applications ranging from molecular electronics and molecular biology too self-assembly of dynamic combinatorial libraries that lead to sophisticated molecular recognition phenomena. ${ }^{11-13}$ In the context of molecular electronics, AuNPs can be regarded as potential ultra-small electrodes, and the unique optical and electronic properties of AuNPs have been explored for development of biosensors and biomedicine. ${ }^{14-23}$

Connecting AuNPs with conducting molecular wires or electrochemically active molecular components is an intriguing thought. If AuNPs are connected via a mechanically interlocked structure, for example a pseudo-rotaxane, one can envisage a molecular wire connecting the AuNPs covered in an insulating layer, thus mimicking the macroscopic design of a copper wire. Success in this area would potentially enable constructing very small electronic components (Fig. 1). 


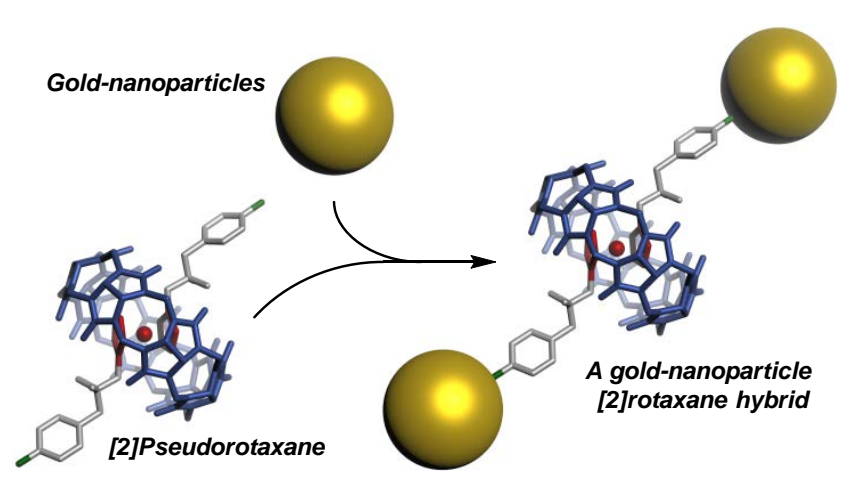

Fig. 1 Schematic representation of the formation of a gold-nanoparticle [2]rotaxane hybrid from a [2]pseudorotaxane and gold-nanoparticles.

Recent developments in the area of supramolecular chemistry of the macrocycles cucurbit $[n]$ urils (CB[n]) in aqueous solution has been utilized to enable formation of very stable pseudo-rotaxanes; in 2007 a bis-dialkylammonium ferrocene compound with an association constant to $\mathrm{CB}$ [7] of $3 \cdot 10^{15} \mathrm{M}^{-1}$ in water was discovered, and in 2014 the first host-guest pair with a dissociation constant as small as $10^{-18} \mathrm{M}$ was reported for $\mathrm{CB}[7] .^{24}$ Such high binding affinities mean that the complexes are essentially completely intact, even at low concentrations, which makes these pseudo-rotaxanes compatible with the concentrations where AuNPs are prepared.

We report here the preparation of a [2]rotaxane with AuNPs functioning as stoppers and an electroactive ferrocene core structure surrounded by a $\mathrm{CB}[7]$ moiety. To achieve this, the preparation of a pseudo-rotaxane with two thiols pointing out of a $\mathrm{CB}[7]$ is essential. Specifically, we describe the synthesis and investigation of two inclusion complexes that are based on the $\mathrm{CB}[7]$ host and a novel ferrocene based bis-ammonium cationic guest molecules functionalised with thiols (Chart 1). The complexes have been systematically characterised by liquid chromatography-mass spectrometry (LC-MS) analysis, 1D and 2D nuclear magnetic resonance (NMR) spectroscopy as well as electrochemical investigations. The electrochemical data are of particular interest as they disclose detailed insight into the dynamics of the pseudo-rotaxane structure. ${ }^{1} \mathrm{HNMR}$ competition experiments reveal strong binding affinities of the complexes $\left(K_{\mathrm{a}} \sim 10^{13} \mathrm{M}^{-1}\right)$ and the possibility of reversibly removing the functionalised guest upon treatment with a competitive guest molecule. Finally, we confirm the formation of a simple [2]rotaxane structure by transmission electron microscopy (TEM).
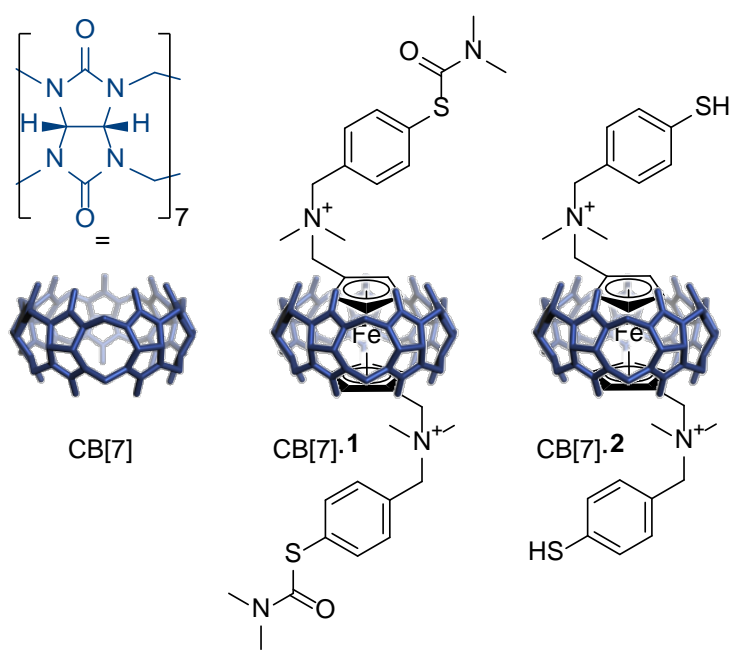

Chart 1 Structures of the $\mathrm{CB}[7]$ host and the inclusion complexes between $\mathrm{CB}[7]$ and the ferrocene guests 1 and 2 reported in this work.

\section{Results and discussion}

\section{Synthesis of the inclusion complexes}

The guest 1 was synthesised using a convergent synthesis strategy (Scheme 1). The phenyl moiety was introduced from 4hydroxybenzaldehyde and the $O$-thiocarbamate formed through a reaction with $\mathrm{N}, \mathrm{N}$-dimethylthiocarbamoyl chloride. A thermally induced Newman-Kwart rearrangement ${ }^{25}$ converted the $O$-thiocarbamate into the corresponding $S$-thiocarbamate. Selective reduction using $\mathrm{NaBH}_{4}$ transformed the aldehyde into the alcohol and was followed by reaction with $\mathrm{PBr}_{3}$ to generate the benzyl bromide intermediate.

The dialkylation of the ferrocene moiety was conducted through lithiation of ferrocene with $n$-BuLi followed by in situ reaction with Eschenmoser's salt. ${ }^{26}$ Adding the benzyl bromide intermediate to the alkylated ferrocene intermediate formed the quaternary ammonium cations via a Menshutkin reaction yielding the bromide salt of guest 1 .

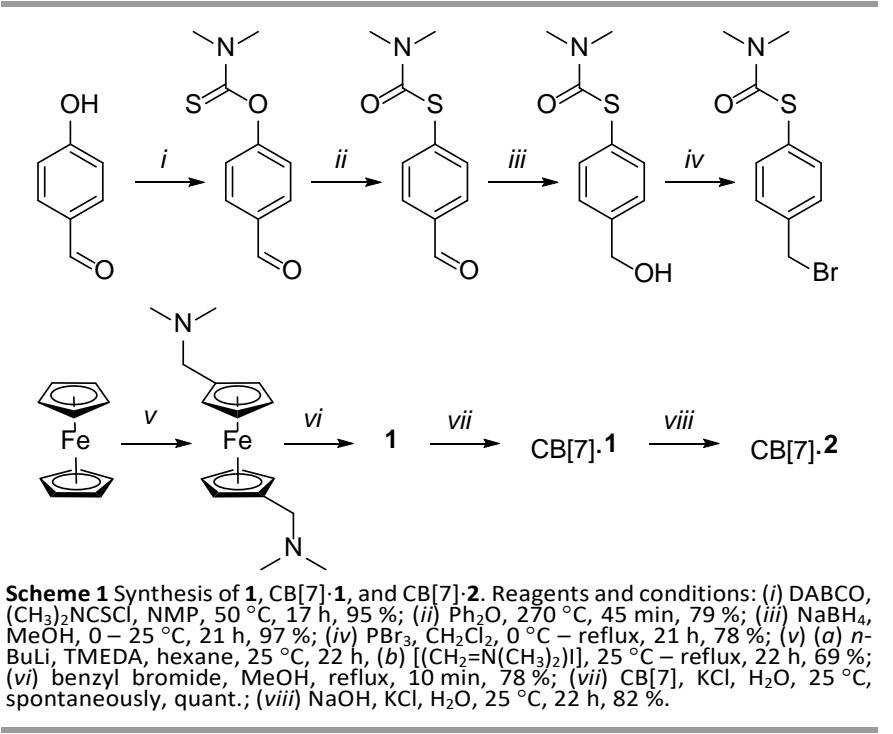


The inclusion complex $\mathrm{CB}[7] \cdot 1$ was formed spontaneously when mixing equimolar amounts of guest 1 together with the $\mathrm{CB}$ [7] host, which was synthesised according to a procedure reported previously. ${ }^{27}$ Subsequent basic hydrolysis of the $S$ thiocarbamates in $\mathrm{CB}[7] \cdot \mathbf{1}$ gave the $\mathrm{CB}[7] \cdot \mathbf{2}$ complex. All compounds were characterised by ${ }^{1} \mathrm{H}$ and ${ }^{13} \mathrm{C}$ NMR spectroscopy, high-resolution ESI mass spectrometry, and elemental analysis thus confirming their identities (see Supporting Information).

\section{Characterisation by NMR spectroscopy}

${ }^{1} \mathrm{H}$ NMR spectroscopic analysis provides an initial assessment of the binding interactions between the cationic ferrocene guests and the $\mathrm{CB}[7]$ host. The ${ }^{1} \mathrm{H}$ NMR spectra of $\mathbf{1}, \mathrm{CB}[7]$, and $\mathrm{CB}[7] \cdot \mathbf{1}$ are shown in Fig. 2a. The complex formation induces changes in the chemical shift values of both $\mathrm{CB}$ [7] and 1. The presence of $\mathrm{CB}[7]$ leads to a pronounced upfield shift of the proton resonances in the cyclopentadienyl $(\mathrm{Cp})$ ring with $\Delta \delta$ values of $0.75 \mathrm{ppm}$ for $H_{\mathrm{G}}$ and $0.83 \mathrm{ppm}$ for $H_{\mathrm{H}}$. In contrast, the signals corresponding to the protons on the substituted phenyl ring $\left(H_{\mathrm{A}}, H_{\mathrm{B}}\right.$, and $\left.H_{\mathrm{C}}\right)$ experience only a small downfield shift. The reverse trend in the two moieties of $\mathbf{1}$ indicates entirely different environments for the ferrocene and phenyl group, showing how the ferrocene residue is positioned inside the cavity of $\mathrm{CB}$ [7] upon complexation, while the phenyl moiety remains outside. The methylene and $N$-methyl protons $\left(H_{\mathrm{D}}\right.$ and $H_{\mathrm{E}}$ ) are less shielded, moving upfield with $\Delta \delta$ values of 0.11 and $0.04 \mathrm{ppm}$, respectively, which indicates that they are closer to the cavity than the protons $H_{\mathrm{A}}-H_{\mathrm{c}}$. Finally, the methylene protons $\left(H_{\mathrm{F}}\right)$ that bridge the ferrocene unit to the positively charged nitrogen are shifted upfield $(\Delta \delta 0.64 \mathrm{ppm})$ along with the ferrocene protons, providing clear evidence that they are all fully included by $\mathrm{CB}[7]$. Similar spectral changes were observed for $\mathrm{CB}$ [7].2 (Fig. 2a, bottom).

A 2D ROESY experiment on the complex $\mathrm{CB}[7] \cdot 1$ further supports that the ferrocene moiety in $\mathbf{1}$ is located inside the cavity of $\mathrm{CB}[7]$. The ${ }^{1} \mathrm{H}-{ }^{1} \mathrm{H}$ ROESY spectrum displays strong electronic couplings shown as NOE cross peaks from $H_{G}$ and $H_{H}$ on ferrocene to $\mathrm{CB}$ [7] proton $H_{\mathrm{J}}$ and none to $H_{1}$ (Fig. 2b). This suggests that the ferrocene moiety and the cavity of $\mathrm{CB}$ [7] are in close proximity through space thus forming the inclusion complex $\mathrm{CB}[7] \cdot \mathbf{1}$.

Diffusion ordered ${ }^{1} \mathrm{H}$ NMR spectroscopy (DOSY) on $\mathrm{CB}[7] \cdot 1$ was consistent with the presence of a single species in solution with a diffusion coefficient $(D)$ of $3.8 \cdot 10^{-6} \mathrm{~cm}^{2} \mathrm{~s}^{-1}$ (Fig. 2c). This result points towards a high association constant between $\mathrm{CB}$ [7] and $\mathbf{1}$, as the DOSY peaks for these two species converge, showing how the host and guest diffuse together as a single molecular entity. Adding excess $\mathrm{CB}$ [7] to this sample resulted in two sets of separated signals with different diffusion coefficients; one corresponding to $\mathrm{CB}[7] \cdot 1$ with a lower $D$ value and one with a higher value corresponding to the smaller $\mathrm{CB}$ [7] species $\left(D_{\mathrm{CB}[7]}=4.2 \cdot 10^{-6} \mathrm{~cm}^{2} \mathrm{~s}^{-1}\right.$; Fig. $\left.2 \mathrm{~d}\right)$.

The NMR spectroscopic data thus provide strong evidence for the location of the $\mathrm{CB}[7]$ host around the ferrocene residue in the $\mathrm{CB}[7] \cdot 1$ and $\mathrm{CB}[7] \cdot \mathbf{2}$ complexes. a)
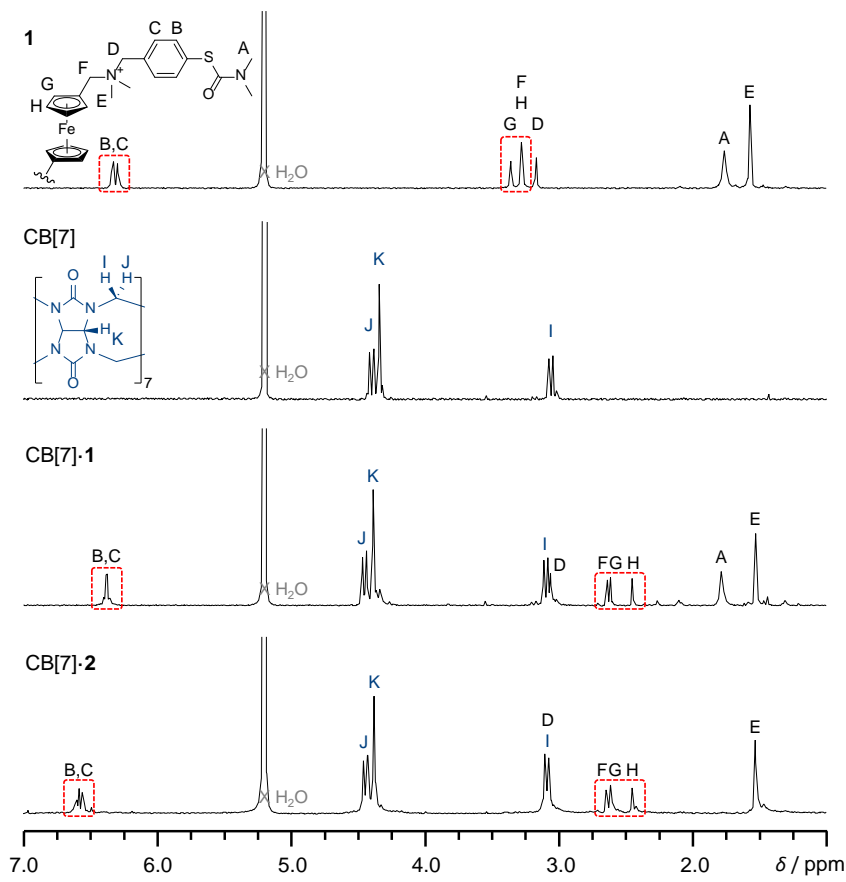

b)

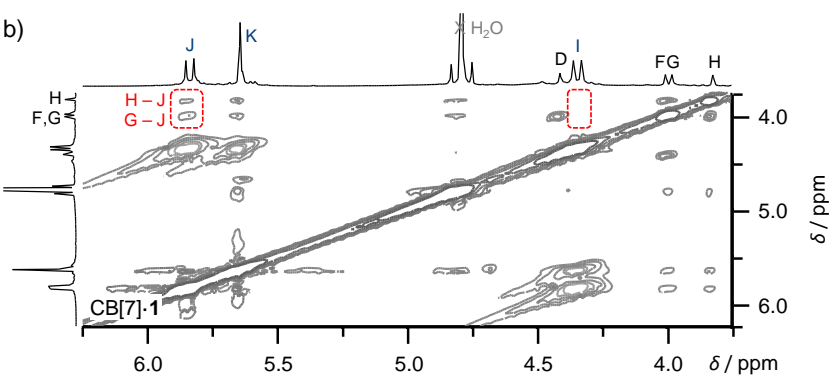

c)

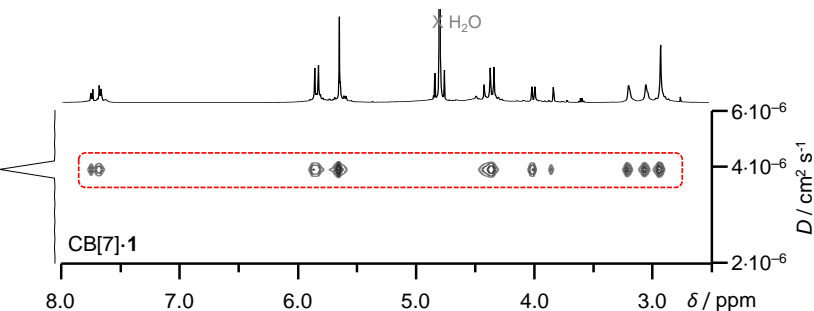

d)

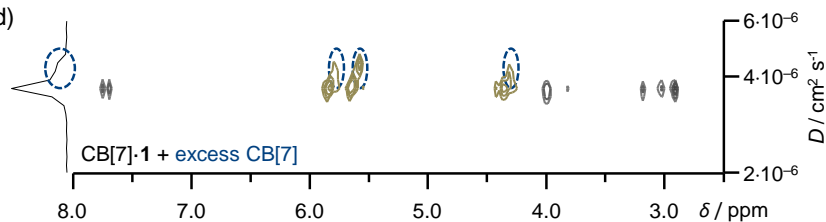

Fig. $2 \mathrm{NMR}$ analysis of the compounds synthesised showing a) stacked ${ }^{1} \mathrm{H}$ NMR spectra $\left(100 \mathrm{~mm} \mathrm{KCl}\right.$ in $\left.4 \mathrm{~m} \mathrm{DCl}(\mathrm{aq}), 500 \mathrm{MHz}, 25^{\circ} \mathrm{C}\right)$ of $1, \mathrm{CB}[7], \mathrm{CB}[7] \cdot \mathbf{1}$, and $\left.\mathrm{CB}[7] \cdot \mathbf{2} ; b\right)$ partial ${ }^{1} \mathrm{H}-{ }^{-1} \mathrm{H}$ ROESY spectrum $\left(500 \mathrm{MHz}, 100 \mathrm{mM} \mathrm{KCl}\right.$ in D2O, $25^{\circ} \mathrm{C}$ ) of $\left.\mathrm{CB}[7] \cdot 1 ; c\right){ }^{1} \mathrm{H}$ DOSY spectrum $\left(500 \mathrm{MHz}, 100 \mathrm{mM} \mathrm{KCl}\right.$ in D2O, $\left.25^{\circ} \mathrm{C}\right)$ of CB[7] $\cdot 1\left(D_{\mathrm{CB}[7] \cdot 1}=3.8 \cdot 10^{-6} \mathrm{~cm}^{2} \mathrm{~s}^{-1}\right)$; and $\left.d\right)^{1} \mathrm{H} \mathrm{DOSY}^{\circ}$ spectrum $\left(500 \mathrm{MHz}, 100 \mathrm{mM} \mathrm{KCl}\right.$ in $\left.\mathrm{D} 2 \mathrm{O}, 25^{\circ} \mathrm{C}\right)$ of $\mathrm{CB}[7] \cdot 1$ added excess $\mathrm{CB}[7]$ where the blue signals arise from excess $\mathrm{CB}[7]\left(D_{\mathrm{CB}[7]}=4.2 \cdot 10^{-6} \mathrm{~cm}^{2} \mathrm{~s}^{-1}\right)$. Assignment of the signals is based on the labelling shown on the structures in the figure. 


\section{Association constants}

In the preliminary ${ }^{1} \mathrm{H}$ NMR experiments it was observed that the $\mathrm{CB}[7] \cdot \mathbf{1}$ and $\mathrm{CB}$ [7]. 2 complexes formed quantitatively with only millimolar concentrations of host and guest, suggesting that the association constant $\left(K_{\mathrm{a}}\right)$ is high. Further, ${ }^{1} \mathrm{H}$ NMR spectra of $\mathrm{CB}[7] \cdot 1$ when an excess amount of guest was present showed how the signals of the free and bound guest were simultaneously observed, revealing that the rate of exchange between these species is slow on the NMR time scale. These findings were anticipated since similar observations in other $\mathrm{CB}[7] \cdot$ ferrocene complexes have been reported, where the high stability was proven through extremely high binding affinities $\left(10^{9}-10^{15} \mathrm{~m}^{-1}\right) \cdot \cdot^{24,28,29}$

The large association constant precludes determination of $K_{\mathrm{a}}$ for the complex formation between $\mathrm{CB}[7]$ and $\mathbf{1}$ directly by NMR spectroscopy as they exceed the experimentally accessible range $\left(10<K_{\mathrm{a}}<10^{4} \mathrm{~m}^{-1}\right) .{ }^{30}$ Instead, a competition ${ }^{1} \mathrm{H}$ NMR spectroscopic experiment was carried out, where guest 1 together with a reference guest $\left(1,1^{\prime}\right.$-bis $(N, N, N$ trimethylammoniomethyl)ferrocene, 3$)^{29}$ was allowed to compete for a limited amount of the host, $\mathrm{CB}[7]$. With this procedure an association constant of $1.1 \cdot 10^{13} \mathrm{M}^{-1}$ for the complexation between $\mathrm{CB}$ [7] and 1 in $100 \mathrm{~mm} \mathrm{KCl}$ in $\mathrm{D}_{2} \mathrm{O}$ was determined (Supporting Information, Section S3).

The $K_{\mathrm{a}}$ value obtained for $\mathrm{CB}[7] \cdot 1$ is one of the highest binding affinities reported for a monovalent synthetic hostguest complex and is comparable in strength to the in supramolecular chemistry and biology widely used Avidin-Dbiotin pair. ${ }^{31}$ This result represents the unique binding properties of $\mathrm{CB}[7]$ towards the guest 1 and shows that high binding affinities competitive with biologically receptor molecules can be achieved for purely synthetic systems.

Our attempts to obtain single crystals of $\mathrm{CB}[7] \cdot 1$ and $\mathrm{CB}[7] \cdot 2$ suitable for X-ray diffraction analysis failed, verifying the difficulties often encountered when trying to crystallize $\mathrm{CB}[7]$.guest complexes. ${ }^{32}$ However, the crystal structure of the complex $\mathrm{CB}[7] \cdot 3$ previously obtained can be used as a model to describe the core interactions in $\mathrm{CB}[7] \cdot \mathbf{1 . 2 4}$ Here, the X-ray structure shows how the ferrocene residue is included by the $\mathrm{CB}$ [7] cavity filling approximately $55 \%$ of the host cavity volume, which is the optimum cavity-filling fraction as proposed by Mecozzi and Rebek. ${ }^{33}$ The near perfect size/shape complementarity between the rigid $\mathrm{CB}[7]$ cavity and the ferrocene moiety is another factor leading to the formation of the highly stable $\mathrm{CB}[7] \cdot \mathbf{1}$ complex.

\section{Characterisation by LC/MS}

Mass spectrometry is now an important tool for characterisation of stable inclusion complexes in the gas phase. The technique can provide unique insight into the formation of the complexes, their stoichiometries, and thereby serve as a supplement to condensed phase studies. ${ }^{34} \mathrm{~A}$ combination of high performance liquid chromatography (HPLC) and highresolution electrospray ionization time-of-flight mass spectrometry (HR-ESI-TOF-MS) was employed for the studies of the inclusion complexes $\mathrm{CB}[7] \cdot \mathbf{1}$ and $\mathrm{CB}[7] \cdot \mathbf{2}$. Fig. 3a shows the
HPLC chromatograms of $1, C B[7] \cdot 1$, and $C B[7] \cdot 2$ monitored at $255 \mathrm{~nm}$ where $\mathrm{CB}$ [7] alone is not UV active. Each chromatogram presents one sharp, well-defined peak with a retention time of 2.6, 2.1, and 1.7 minutes as the analyte changes from 1 through $\mathrm{CB}[7] \cdot \mathbf{1}$ to $\mathrm{CB}[7] \cdot \mathbf{2}$. The distinct peaks indicate that the inclusion complexes persist throughout the column and do not degrade or dissociate.

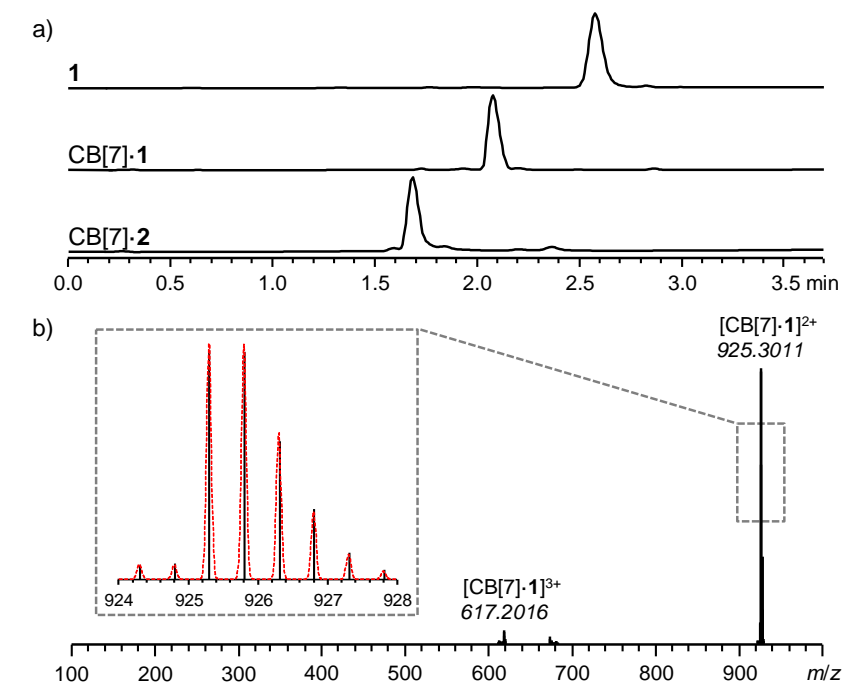

Fig. 3 LC/MS analysis of the target compounds showing $a$ ) stacked HPLC chromatograms (255 nm) of 1 (top), CB[7]·1 (middle), and CB[7]·2 (bottom), and b) HR-ESI-TOF-MS spectrum of $\mathrm{CB}$ [7]-1. The inset shows a zoom of the isotopic distribution of the main peak where the calculated distribution is shown as red dotted lines while the black lines are the measured spectrum.

The corresponding mass spectrum of $\mathrm{CB}[7] \cdot \mathbf{1}$ is shown in Fig. $3 \mathrm{~b}$ where the main peak in the spectrum, at $m / z$ ratio of 925.3011 , is a doubly charged peak shown in the inset together with the calculated isotopic distribution. This peak is consistent with one doubly charged bis-ammonium cation 1 enclosed by the neutral $\mathrm{CB}[7]$ host, $[\mathrm{CB}[7] \cdot 1]^{2+}$, verifying the $1: 1$ inclusion complex. $\mathrm{A}$ second minor peak, at $m / z$ ratio of 617.2016 , which match the triply charged inclusion complex $[\mathrm{CB}[7] \cdot 1]^{3+}$ is also present. We suggest that the third positive charge is acquired through oxidation of the ferrocene unit in the compound thereby reflecting the relative ease of oxidation of the ferrocene/ferrocenium unit in the compound (see the electrochemical characterisation section below), as seen previously for related compounds. ${ }^{35}$

Non-covalent complexes tend to dissociate during LC/MS runs. This can happen both when the complex passes through the polar, aqueous mobile phase in the column of the HPLC or in the spray process in the mass spectrometer, where the association energy of the complex becomes lower than the dissociation energy. However, here the $\mathrm{CB}[7] \cdot \mathbf{1}$ complex persisted throughout the column as well as in the transition from solution to gas phase and was detected without any fragmentation, testifying to a high association energy of $\mathrm{CB}[7] \cdot 1$. Similar results were obtained with $\mathrm{CB}[7] \cdot 2$ (Supporting Information, Fig. S34).

\section{Electrochemical characterisation}


Ferrocene derivatives are electrochemically active, exhibiting fast and reversible one-electron oxidation. ${ }^{36}$ This offers an additional approach to examine the $\mathrm{CB}$ [7]-guest host-guest interactions. We investigated the electrochemical properties of the ferrocene derivatives in the absence and presence of the $\mathrm{CB}$ [7] host in aqueous solution using cyclic voltammetry (CV). The cyclic voltammogram of $\mathbf{1}$ shows one set of well-defined peaks corresponding to reversible one-electron transfer of the ferrocene $(\mathrm{Fc}) /$ ferrocenium $\left(\mathrm{Fc}^{+}\right)$couple at a midpoint redox potential $\left(E^{\circ}\right)$ of $670 \mathrm{mV}$ vs. saturated calomel electrode (SCE), Fig. 4. A large anodic tail is observed at higher potential (>900 mV vs. SCE) and is caused by the oxidation of bromide counter ions to the ammonium cations in $\mathbf{1}$, to bromine (Supporting Information, Fig. S6).

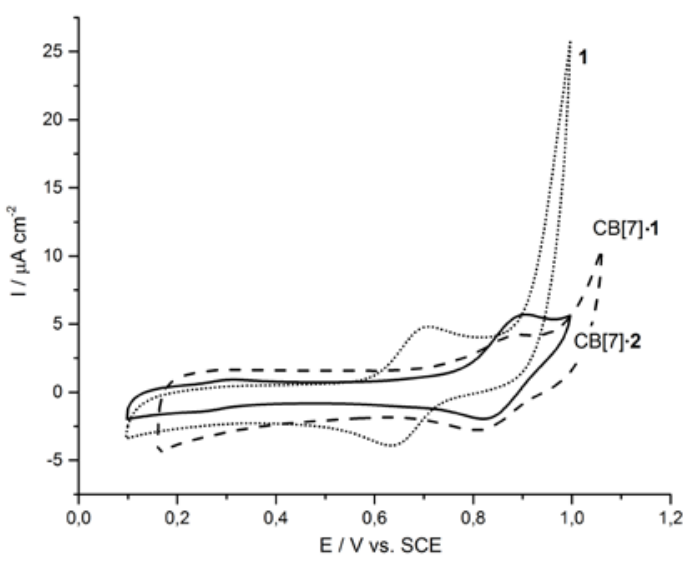

Fig. 4 Cyclic voltammograms of $\mathbf{1}$ (dotted line), CB[7]·1 (dashed line), and CB[7]·2 (continuous line). The samples $(50 \mu \mathrm{m})$ are recorded using a glassy carbon electrode in aqueous $\mathrm{KH}_{2} \mathrm{PO}_{4}(20 \mathrm{~mm}, \mathrm{pH}$ 4.6). Scan rate is $50 \mathrm{mV} / \mathrm{s}$.

The addition of $\mathrm{CB}$ [7] to $\mathbf{1}$ forms the inclusion complex $\mathrm{CB}[7] \cdot 1$ and leads to a pronounced $172 \mathrm{mV}$ anodic shift of the ferrocene $E^{\circ}$ value to $842 \mathrm{mV}$ vs. SCE (Table 1 ). This observation is consistent with the encapsulation of the ferrocene moiety inside the $C B$ [7] cavity. ${ }^{24}, 28,37,38$ An excess of 0.3 equivalents $\mathrm{CB}$ [7] was added to $\mathbf{1}$ to ensure complete formation of the inclusion complex. A reference experiment with $\mathrm{CB}$ [7] alone, in the same potential window, showed no redox activity thus confirming that the peaks observed originate solely from the inclusion complex $\mathrm{CB}[7] \cdot 1$. A large anodic tail in the $\mathrm{CV}$ of $\mathrm{CB}[7] \cdot 1$ at high potential ( $>1.00 \mathrm{~V} v$ s. SCE) is again caused by oxidation of the bromide counter ions in $\mathrm{CB}[7] \cdot 1$.

The anodic shift in $E^{\circ}$ from 1 to $\mathrm{CB}$ [7]-1 reflects the local environmental changes around the ferrocene moiety. The electroneutral reduced ferrocene moiety is considerably stabilized in the complex $\mathrm{CB}[7] \cdot \mathbf{1}$. Upon reduction of the ferrocene centre the resulting anodic shift corresponds to a free energy drop $\left(\Delta \Delta G^{\circ}\right)$ of $16.6 \mathrm{~kJ} \mathrm{~mol}^{-1}$. This decrease is caused by stabilization of the doubly charged reduced ferrocene inside the hydrophobic cavity of $\mathrm{CB}[7]$ relative to the triply charged oxidized form that is less favourable for $\mathrm{CB}[7]$ enclosure, 28,39 i.e. it becomes easier to reduce the oxidized form than for free 1.
The large association constant of $\mathrm{CB}[7] \cdot 1$ is also evidenced by the electrochemical data. The $\mathrm{CV}$ of $\mathrm{CB}[7] \cdot 1$ shows only a single cathodic peak at $802 \mathrm{mV}$ vs. SCE and no signal at $630 \mathrm{mV}$ $v s$. SCE corresponding to pure 1, indicating that the complex has not disassembled.

Table 1 Midpoint redox potentials $\left(E^{\circ}, \mathrm{mV}\right.$ vs. SCE) and potential changes on complexation of free $\mathbf{1}$ and $\mathbf{2}$ with $\mathrm{CB}[7]\left(\Delta E^{\circ}, \mathrm{mV} v \mathrm{vs}\right.$. SCE). The associated changes in Gibbs free energy $\left(\Delta \Delta G^{\circ}, \mathrm{kJ} \mathrm{mol}^{-1}\right)$ are also given. ${ }^{[a]}$

\begin{tabular}{cccc}
\hline Compound & $\begin{array}{c}E^{\circ} \\
{[\mathrm{mV}]}\end{array}$ & $\begin{array}{c}\Delta E^{\circ[\mathrm{b}]} \\
{[\mathrm{mV}]}\end{array}$ & $\begin{array}{c}\left.\Delta \Delta G^{\circ} \mathrm{c}\right] \\
{\left[\mathrm{kJ} \mathrm{mol}^{-1}\right]}\end{array}$ \\
\hline $\mathbf{1}$ & 670 & - & - \\
$\mathrm{CB}[7] \cdot \mathbf{1}$ & 842 & +172 & -16.6 \\
$\mathrm{CB}[7] \cdot \mathbf{2}$ & 855 & +185 & -17.8
\end{tabular}

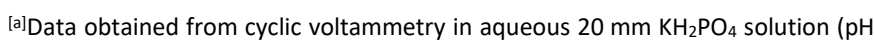
4.6), $25^{\circ} \mathrm{C}$. Scan rate $50 \mathrm{mV} \mathrm{s}{ }^{-1}$. ${ }^{[b]} \Delta E^{\circ}$ values calculated as $E^{\circ}\left(\mathrm{CB}[7]\right.$.guest) $-E^{\circ}(1)$. [c] Obtained using $\Delta \Delta G^{\circ}=-v \cdot F \cdot \Delta E^{\circ}$, where $v$ is the number of electrons transferred in the reaction and $F$ is the Faraday constant.

Similar CVs were observed for $\mathrm{CB}[7] \cdot 2$ with a midpoint redox potential of $855 \mathrm{mV}$ vs. SCE corresponding to an anodic shift of $185 \mathrm{mV}$ vs. 1. This can be ascribed to the same reasons as for 1 and $\mathrm{CB}[7] \cdot 1$. The fact that the complexation is clearly detected at micromolar concentrations supports the high stability of these complexes. In addition, a pair of smaller peaks is observed around $278 \mathrm{mV} v \mathrm{~s}$. SCE. This process is caused by formation of carbonyl and/or quinone compounds on the carbon electrode surface, which is common for chloride containing supporting electrolytes, ${ }^{40}$ corresponding to the fact that chloride anions are the counter ion in $\mathrm{CB}[7] \cdot \mathbf{2}$.

Electrochemical kinetics for 1 and $\mathrm{CB}[7] \cdot 1$ Cyclic voltammetry for solute $\mathbf{1}, \mathrm{CB}[7] \cdot \mathbf{1}$ and $\mathrm{CB}[7] \cdot \mathbf{2}$ at shorter time scales, i.e. at faster scan rates gives voltammetric signals that display different patterns for the three compounds (Supporting Information, Fig. S7). 1 follows a diffusion controlled electrochemical process for scan rates up to $0.5 \mathrm{~V} \mathrm{~s}^{-1}$, with both the anodic $\left(i_{p a}\right)$ and cathodic peak current $\left(i_{p c}\right)$ following a scan rate $(v)$ dependence, $i_{p a, c} \propto v^{x}, x \approx 1 / 2\left(R^{2}=0.996 \pm 0.001\right.$, see Supporting Information, Fig. S8 and S9). This roughly applies also to $\mathrm{CB}[7] \cdot 1$, although formally with a slightly higher $x \approx 0.6$. For 1 the peaks separate at scan rates higher than $0.5 \mathrm{~V} \mathrm{~s}^{-1}$, where kinetic control and "quasi-reversible" behaviour gradually take over (see further discussion below and Supporting Information, Fig. S11).

The diffusion coefficients $\left(D_{\circ}\right)$ of the electroactive species were obtained using the Randles-Sevčik equation (Eq. 1), ${ }^{41}$

$i_{p}=0.4463 \cdot n \cdot F \cdot A \cdot c \cdot \sqrt{\frac{n \cdot F \cdot v \cdot D_{0}}{R \cdot T}}$

where $n$ is the number of electrons in the redox process, $F$ is the Faraday constant, $A$ the electrode area, $c$ the concentration of the compound, $R$ the gas constant, and $T$ the absolute temperature. The resulting $D_{0}$ are listed in Table 2 .

Among other determinants the diffusion coefficient depends on the size (diameter) of the molecule. ${ }^{42}$ As the $\mathrm{CB}[7] \cdot 1$ complex is bulkier than its free counterparts, its diffusion coefficient determined from eq. (1) is similarly smaller (Table 2) reflecting the larger hydrodynamic radius of the complex, as 
seen previously for related systems. ${ }^{38} D_{0}$ for $\mathrm{CB}[7] \cdot \mathbf{1}$ is thus less than half of the value for $1\left((6.3 \pm 0.7) \cdot 10^{-7} \mathrm{~cm}^{2} \mathrm{~s}^{-1}\right.$ vs $\left.(1.5 \pm 0.4) \cdot 10^{-6} \mathrm{~cm}^{2} \mathrm{~s}^{-1}\right)$, roughly following the diameter of the molecules.

1 and $\mathrm{CB}[7] \cdot 1$ thus display consistent diffusion behaviour. The calculated $D_{0}$ for $\mathrm{CB}[7] \cdot 2$, based on eq.(1), is, however, 16 times that for $\mathrm{CB}$ [7]-1 of comparable size, and six times of that for 1 . This abnormally large $D_{0}$ value for $\mathrm{CB}[7] \cdot 2$ almost certainly suggests a different electron transfer mechanism for $\mathrm{CB}[7] \cdot \mathbf{2}$. While $D_{0}$ for 1 and CB[7].1 in Table 2 can be regarded as real diffusion coefficients, $D_{0}$ for $\mathrm{CB}[7] \cdot 2$ must therefore instead be denoted as "apparent".

Table 2 Diffusion coefficients $\left(D_{0}, \mathrm{~cm}^{2} \mathrm{~s}^{-1}\right)$ and heterogeneous electron transfer rate constants $\left(k_{\mathrm{s}}, \mathrm{cm} \mathrm{s}^{-1}\right)$ obtained for $\mathbf{1}$ (real), $\mathrm{CB}[7] \cdot \mathbf{1}$ (real) and $\mathrm{CB}[7] \cdot \mathbf{2}$ (apparent). ${ }^{[\mathrm{a}}$

\begin{tabular}{cccc}
\hline Compound & $\mathrm{pH}$ & $\begin{array}{c}D_{\mathrm{o}} \\
{\left[\mathrm{cm}^{2} \mathrm{~s}^{-1}\right]}\end{array}$ & $\begin{array}{c}k_{\mathrm{s}} \\
{\left[\mathrm{cm} \mathrm{s}^{-1}\right]}\end{array}$ \\
\hline 1 & 4.6 & $(1.5 \pm 0.4) \cdot 10^{-6}$ & $(1.4 \pm 0.1) \cdot 10^{-2}$ \\
$\mathrm{CB}[7] \cdot 1$ & 4.6 & $(6.3 \pm 0.7) \cdot 10^{-7}$ & $(2.8 \pm 0.2) \cdot 10^{-3}$ \\
$\mathrm{CB}[7] \cdot 2$ & 4.6 & $(9.2 \pm 0.3) \cdot 10^{-5}$ & $(3.9 \pm 0.1) \cdot 10^{-2}$ \\
& 1.4 & $(10.6 \pm 0.1) \cdot 10^{-5}$ & $(59.2 \pm 7.9) \cdot 10^{-2}$
\end{tabular}

[a]The data derived from cyclic voltammetry in either $\mathrm{KH}_{2} \mathrm{PO}_{4}(20 \mathrm{~mm}, \mathrm{pH} 4.6)$ or $\mathrm{HClO}_{4}(20 \mathrm{~mm}, \mathrm{pH} 1.4)$ at $25^{\circ} \mathrm{C}$.

Table 2 also summarizes the real and "apparent" heterogeneous electron transfer rate constants $\left(k_{\mathrm{s}}\right)$ obtained for $\mathbf{1}, \mathrm{CB}[7] \cdot \mathbf{1}$, and $\mathrm{CB}[7] \cdot \mathbf{2}$. The ferrocene moiety in $\mathbf{1}$ was found to follow reversible behaviour at low scan rates $\left(<0.5 \mathrm{~V} \mathrm{~s}^{-1}\right)$, according with previous reports for similar systems. ${ }^{35,38,43}$ Reversible processes involve fast electron transfer compared to the scan rate with only transient surface interaction between the electrode and the reagents, and peak separation of $59 \mathrm{mV}$ (for a one-electron transfer) independent of the scan rate. ${ }^{42}$ Approximately this behaviour was observed for $\mathbf{1}$ as evidenced by the invariance of the peak-to-peak splitting $\left(\Delta E_{\mathrm{p}}=79 \pm 1 \mathrm{mV}\right)$ as the scan rate increased up to about $0.5 \mathrm{~V} \mathrm{~s}^{-1}$. The $\Delta E_{\mathrm{p}}$ value is somewhat higher than the theoretical value of $59 \mathrm{mV}$ which may be caused by small distortions due to solution resistance effects. ${ }^{44}$

When the scan rate was increased to $4 \mathrm{~V} \mathrm{~s}^{-1}$ the difference between the anodic and cathodic midpoint potentials of $\mathbf{1}$ was found to increase, indicating that the scan rate is now faster than the electron transfer process, and the process thus changes from reversible to quasi-reversible. The heterogeneous electron transfer rate constant, $k_{\mathrm{s}}$ for $\mathbf{1}$ was determined for the quasi-reversible process using Nicholson's Method (Eq. 2), 45 and calculated at given scan rates using the parameter $\Psi$, which is based on the experimental $\Delta E_{\mathrm{p}}$ values, i.e.

$\Psi=\frac{\left(D_{o} / D_{R}\right)^{\alpha / 2} \cdot k_{s} \cdot \sqrt{R \cdot T}}{\sqrt{D_{o} \cdot \pi \cdot n \cdot F \cdot v}}$

where $D_{0}$ and $D_{\mathrm{R}}$ are the diffusion coefficients of the oxidized and reduced species and $\alpha$ the transfer coefficient. Taking $D_{\mathrm{o}}=D_{\mathrm{R}}$ and $\alpha=0.5, k_{\mathrm{s}}$ for 1 was determined for all applied scan rates and found to be $k_{\mathrm{s}}=(1.4 \pm 0.1) \cdot 10^{-2} \mathrm{~cm} \mathrm{~s}^{-1}$ independent of the scan rate (Table 2 , and Supporting Information).
The complex $\mathrm{CB}[7] \cdot \mathbf{1}$ displays quasi-reversible behaviour at scan rates higher than $50 \mathrm{mV} \mathrm{s}^{-1}$. The midpoint potential separation increases linearly from 79 to $325 \mathrm{mV}$ as the scan rate increases from 0.05 to $4.00 \mathrm{~V} \mathrm{~s}^{-1}$. The heterogeneous electron transfer rate constant was determined for $\mathrm{CB}[7] \cdot 1$ similarly as for 1 , giving $k_{\mathrm{s}}=(2.8 \pm 0.2) \cdot 10^{-3} \mathrm{~cm} \mathrm{~s}^{-1}$.

The rate constant values in Table 2 show that encapsulation of the ferrocene moiety in $\mathbf{1}$ into the complex $\mathrm{CB}[7] \cdot \mathbf{1}$ reduces the electrochemical rate constant by a factor of five. A similar trend was observed in related $\mathrm{CB}[7]$.guest inclusion complexes. ${ }^{38}$ The smaller rate constant can be understood by viewing the $\mathrm{CB}[7]$ macrocycle either as an additional physical barrier for electron tunnelling, or as caused by pre-organization of the $\mathrm{CB}[7] \cdot 1$ complex towards more favourable electron transfer ("gated electron transfer") ${ }^{46}$ adding an additional activation energy contribution. We address this difference further in the Conclusion Section.

Interfacial electrochemical kinetics for $\mathrm{CB}$ [7]-2 The mechanistic electron transfer dynamics of $\mathrm{CB}[7] \cdot \mathbf{2}$ is different from that of $\mathbf{1}$ and $\mathrm{CB}[7] \cdot 1$. The abnormal values of the "apparent" diffusion coefficient and interfacial electron transfer rate constant based on the diffusion formalism were noted. In addition the $i_{p a, c} \propto v^{x}$ correlation accords poorly with $\mathrm{x} \approx 0.5$ but shows instead a $i_{p a, c}$ $\propto v^{0.8-0.9}$ behaviour (Supporting Information, Fig. S8 and S9). The diffusion formalism represented by eqs. (1) and (2) therefore does represent well the voltammetry of $\mathrm{CB}[7] \cdot 2$, which accords much better with monolayer voltammetry. This is understandable if the thiolate linker group of $\mathrm{CB}[7] \cdot 2$ is adsorbed more strongly on the glassy carbon electrode surface than the thiocarbamate linkers of $\mathbf{1}$ and $\mathrm{CB}[\mathbf{7}] \cdot \mathbf{1}$. It is not a priori obvious that this should be so, but the obviously different voltammetric behaviour is a strong indication that this is indeed the case.

Interfacial electrochemical electron transfer kinetics for $\mathrm{CB}[7] \cdot \mathbf{2}$ is then more appropriately based on Laviron analysis. ${ }^{47}$ For the sake of completion, the Laviron analysis based standard electron transfer rate constant was calculated from the variation of the peak separation with increasing scan rate. With the reservation that the peak separations are on the small side for ideal Laviron analysis, the rate constant was found to be $40 \mathrm{~s}^{-1}$ (Supporting Information, Section S5.6) robust up to $10 \mathrm{~V}$ $\mathrm{s}^{-1}$ and $200 \mathrm{mV}$ peak separation. This is in fact a remarkably high value testifying to highly efficient interfacial electrochemical electron transfer and strong bonding between the thiolate functionality on $\mathrm{CB}[7] \cdot 2$ and the glassy carbon electrode.

The different mechanisms and rate constant units mean, however, that the diffusion controlled and surface controlled rate constants $\left(k_{\mathrm{s}}\right.$ in $\left.\mathrm{cm} \mathrm{s}^{-1} \mathrm{vs} \mathrm{s}^{-1}\right)$ cannot be compared directly. In the Conclusion Section we therefore focus on the comparison of the diffusion based interfacial electrochemical rate constants of 1 and CB[7].1 with details given in the Supporting Information, Sections S5.5-S5.7.

\section{Connecting gold nanoparticles}

By utilizing the free thiol functionalities in $\mathrm{CB}$ [7]-2 it was proven possible to build a gold nanoparticle (AuNP) capped [2]rotaxane that is soluble in water. The [2]rotaxane is constructed from a 
single [2]pseudorotaxane $\mathrm{CB}[7] \cdot 2$ in the centre that is used as an organic linker to connect two AuNP "stoppers" by selfassembly of the thiols onto the gold surfaces. To show the general nature of the concept, the assembly was carried out using two different sizes of nanoparticles in similar experimental conditions. Notably, a solution of $\mathrm{CB}[7] \cdot 2$ was exposed to either 12 or $60 \mathrm{~nm}$ citrate stabilized gold nanoparticles. After initial reaction, the nanoparticles dimers were purified using centrifugation (See Supporting Information, Section $\mathbf{S 6}$ for details).

Transmission electron microscopy (TEM) provided structural information on the [2]rotaxane "hybrid" (Fig. 5). The gold nanoparticles appear clearly as solid spheres (12 or $60 \mathrm{~nm}$ in diameter) while the [2]pseudorotaxane $\mathrm{CB}[7] \cdot 2$ with a diameter of only $\sim 1.5 \mathrm{~nm}$ is too small to see in the images. Without the addition of $\mathrm{CB}[7] \cdot 2$ the gold nanoparticles are dispersed individually. The presence of $\mathrm{CB}[7] \cdot 2$ triggers formation of AuNP dimers binding two gold nanoparticles together, and forming the desired [2]rotaxane. We note that nanoparticle rotaxane oligomers can be formed during the synthesis, but these higher density structures are removed during centrifugation. ${ }^{48}$

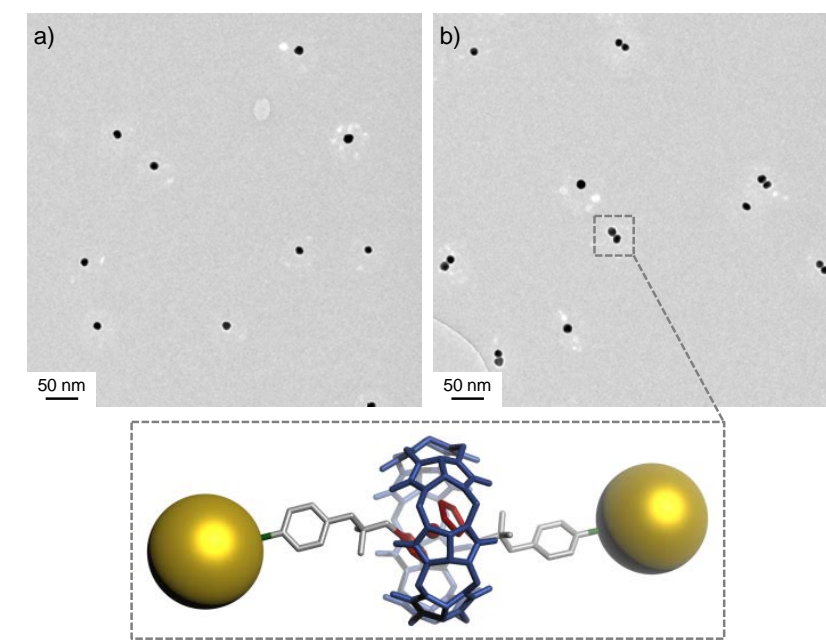

Fig. 5 TEM images of the gold nanoparticle capped [2]rotaxane showing $a$ ) reference AuNP (12 nm diameter, no CB[7]·1 added) and $b$ ) after addition of $\mathrm{CB}[7] \cdot 1$ with a zoom of a cartoon showing the structure of the [2] rotaxane.

\section{Conclusions}

We have described a nanoparticle-stoppered [2] rotaxane based on an exceptionally stable pseudo-rotaxane featuring an electroactive ferrocene rod encapsulated in a cucurbit[7]uril macrocycle. The pure and nano-stoppered rotaxanes have been characterised comprehensively, and the interfacial electrochemical electron transfer patterns rationalized by a transparent frame of molecular charge transfer theory. Particularly we have been able to conclude that the electrochemical electron transfer kinetics proceeds via diffusion for 1 and $C B[7] \cdot 1$ while CB[7]·2 most likely operates via a highly efficient surface controlled mechanism. With these discoveries we have opened new avenues to prepare and manipulate nanosized objects and systems, where a single or a few isolated active molecules constitute the active units. With the enormous progress in the preparation of molecular machines seen in the past decades we believe that this work can pave the way to an entirely new type of nano-sized molecular machines.

\section{Conflicts of interest}

There are no conflicts to declare.

\section{Acknowledgements}

This work was supported by the Lundbeck Foundation and the Danish Council for Independent Research (Sapere Aude, DFF 4148-002606) (M.P.), the Lundbeck Foundation (R141-201313273) (J.Z.), and the European Research Council (ERC-StG (G.A. 337221 SIMONE) (L. S. and K.M.-P.) We thank Christian G. Tortzen for his assistance with the ${ }^{1} \mathrm{H}-{ }^{1} \mathrm{H}$ ROESY and ${ }^{1} \mathrm{H}$ DOSY NMR experiments.

\section{Notes and references}

1. J. F. Stoddart, Angew. Chem. Int. Ed., 2017, 56, 11094-11125.

2. T. R. Kelly, H. De Silva and R. A. Silva, Nature, 1999, 401, 150-152.

3. N. Koumura, R. W. J. Zijlstra, R. A. van Delden, N. Harada and B. L. Feringa, Nature, 1999, 401, 152-155.

4. C.-F. Lee, D. A. Leigh, R. G. Pritchard, D. Schultz, S. J. Teat, G. A. Timco and R. E. P. Winpenny, Nature, 2009, 458, 314.

5. S. D. P. Fielden, D. A. Leigh and S. L. Woltering, Angew. Chem. Int. Ed., 2017, 56, 11166-11194.

6. C. H. L. Nicole and E. J. Sophie, J. Phys.: Condens. Matter, 2015, 27, 354101.

7. J. D. Hegemann, M. Zimmermann, X. Xie and M. A. Marahiel, Acc. Chem. Res., 2015, 48, 1909-1919.

8. S. S. Jang, Y. H. Jang, Y.-H. Kim, W. A. Goddard, A. H. Flood, B. W. Laursen, H.-R. Tseng, J. F. Stoddart, J. O. Jeppesen, J. W. Choi, D. W. Steuerman, E. Delonno and J. R. Heath, J. Am. Chem. Soc., 2005, 127, 1563-1575.

9. Q. Zhang, W. Z. Wang, J. J. Yu, D. H. Qu and H. Tian, Adv. Mater., 2017, 29, 1604948.

10. Q. Zhang and D. H. Qu, ChemPhysChem, 2016, 17, 1759-1768.

11. A. K. Boal and V. M. Rotello, J. Am. Chem. Soc., 2000, 122, 734735.

12. P. Nowak, V. Saggiomo, F. Salehian, M. Colomb-Delsuc, Y. Han and S. Otto, Angew. Chem. Int. Ed., 2015, 54, 4192-4197.

13. A. Cecconello, C.-H. Lu, J. Elbaz and I. Willner, Nano Lett., 2013, 13, 6275-6280.

14. M.-C. Daniel and D. Astruc, Chem. Rev., 2004, 104, 293-346.

15. E. Katz and I. Willner, Angew. Chem. Int. Ed., 2004, 43, 60426108.

16. A. M. Alkilany, S. E. Lohse and C. J. Murphy, Acc. Chem. Res., 2013, 46, 650-661.

17. M. R. Dewi, T. A. Gschneidtner, S. Elmas, M. Ranford, K. MothPoulsen and T. Nann, ACS Nano, 2015, 9, 1434-1439.

18. L. Sun, Y. A. Diaz-Fernandez, T. A. Gschneidtner, F. Westerlund, S. Lara-Avila and K. Moth-Poulsen, Chem. Soc. Rev., 2014, 43, 7378-7411.

19. Y. D. Fernandez, L. Sun, T. Gschneidtner and K. Moth-Poulsen, APL Materials, 2014, 2, 010702. 
20. T. A. Gschneidtner, Y. A. Diaz Fernandez and K. Moth-Poulsen, J. Mater. Chem. C, 2013, 1, 7127-7133.

21. A. Guttman, D. Mahalu, J. Sperling, E. Cohen-Hoshen and I. BarJoseph, Appl. Phys. Lett., 2011, 99, 063113.

22. A. B. Petersen, E. Thyrhaug, T. Jain, K. Kilsaa, M. Bols, K. MothPoulsen, N. Harrit and T. Bjørnholm, J. Phys. Chem. B, 2010, 114, 11771-11777.

23. S. Karmakar, S. Kumar, P. Marzo, E. Primiceri, R. Di Corato, R. Rinaldi, P. G. Cozzi, A. P. Bramanti and G. Maruccio, Nanoscale, 2012, 4, 2311-2316.

24. M. V. Rekharsky, T. Mori, C. Yang, Y. H. Ko, N. Selvapalam, H. Kim, D. Sobransingh, A. E. Kaifer, S. Liu, L. Isaacs, W. Chen, S. Moghaddam, M. K. Gilson, K. Kim and Y. Inoue, Proc. Natl. Acad. Sci. U. S. A., 2007, 104, 20737-20742.

25. G. C. Lloyd-Jones, J. D. Moseley and J. S. Renny, Synthesis, 2008, 2008, 661-689.

26. C. Glidewell, B. J. L. Royles and D. M. Smith, J. Organomet. Chem., 1997, 527, 259-261.

27. C. Marquez, H. Fang and W. M. Nau, IEEE Trans. Nanobiosci., 2004, 3, 39-45.

28. W. S. Jeon, K. Moon, S. H. Park, H. Chun, Y. H. Ko, J. Y. Lee, E. S. Lee, S. Samal, N. Selvapalam, M. V. Rekharsky, V. Sindelar, D. Sobransingh, Y. Inoue, A. E. Kaifer and K. Kim, J. Am. Chem. Soc., 2005, 127, 12984-12989.

29. L. Cao, M. Šekutor, P. Y. Zavalij, K. Mlinarić-Majerski, R. Glaser and L. Isaacs, Angew. Chem. Int. Ed., 2014, 53, 988-993.

30. C. A. Schalley, Analytical Methods in Supramolecular Chemistry, WILEY-VCH Verlag GmbH \& Co. KGaA, 2007.

31. N. M. Green, Biochem. J, 1963, 89, 585-591.

32. D. Bardelang, K. A. Udachin, D. M. Leek, J. C. Margeson, G. Chan, C. I. Ratcliffe and J. A. Ripmeester, Cryst. Growth Des., 2011, 11, 5598-5614.

33. S. Mecozzi and J. J. Rebek, Chem. Eur. J., 1998, 4, 1016-1022.

34. F. Yang and D. V. Dearden, Isr. J. Chem., 2011, 51, 551-558.

35. S. Yi, W. Li, D. Nieto, I. Cuadrado and A. E. Kaifer, Org. Biomol. Chem., 2013, 11, 287-293.

36. N. G. Connelly and W. E. Geiger, Chem. Rev., 1996, 96, 877-910.

37. W. Ong and A. E. Kaifer, Organometallics, 2003, 22, 4181-4183.

38. L. Cui, S. Gadde, W. Li and A. E. Kaifer, Langmuir, 2009, 25, 1376313769.

39. S. Senler, W. Li, M. H. Tootoonchi, S. Yi and A. E. Kaifer, Supramol. Chem., 2014, 26, 677-683.

40. R. C. Engstrom and V. A. Strasser, Anal. Chem., 1984, 56, 136-141.

41. J. E. B. Randles, Transactions of the Faraday Society, 1948, 44, 327-338.

42. A. J. Bard and L. R. Faulkner, Electrochemical methods, fundamentals and applications, Wiley, $2^{\text {nd }}$ edn., 2001.

43. S. Gadde and A. E. Kaifer, Curr. Org. Chem., 2011, 15, 27-38.

44. D. K. Gosser, Cyclic voltammetry, simulation and analysis of reaction mechanisms, Wiley, 1993.

45. R. S. Nicholson, Anal. Chem., 1965, 37, 1351-1355.

46. A. M. Kuznetsov and J. Ulstrup, Electron transfer in chemistry and biology - An introduction to the theory, Wiley, Chichester, 1998.

47. E. Laviron, J. Electroanal. Chem. Int. Electrochem., 1979, 101, 1928.

48. F. C.-M. Leung, S. Y.-L. Leung, C. Y.-S. Chung and V. W.-W. Yam, J. Am. Chem. Soc., 2016, 138, 2989-2992. 